\title{
Parenting early adolescents with autism spectrum disorder before and after transition to secondary school
}

Lotte van Esch ${ }^{1,2}$, Liz O'Nions ${ }^{1,2}$, Karin Hannes ${ }^{3}$, Eva Ceulemans ${ }^{4}$, Karla Van Leeuwen ${ }^{1}$, \& Ilse Noens ${ }^{1,2}$

${ }^{1}$ KU Leuven, Parenting and Special Education Research Unit, Leopold Vanderkelenstraat 32 box 3765, 3000 Leuven

${ }^{2}$ Leuven Autism Research (LAuRes)

${ }^{3}$ KU Leuven, Centre for Sociological Research, Parkstraat 45 - bus 3601, 3000 Leuven

${ }^{4}$ KU Leuven, Quantitative Psychology and Individual Differences, Tiensestraat 102 - bus 3713, 3000 Leuven

\begin{abstract}
Although early adolescence is a challenging period for all parents, parents of children with autism spectrum disorder (ASD) face additional challenges. At present, little is known about their concrete parenting behaviors during this stage of their child's development. The main goal of this study was to explore what behaviors parents adopt and investigate how these relate to parenting dimensions previously described in the literature. In addition, we aimed to explore the feelings and cognitions of parents regarding their parenting behavior. Parents of seventeen early adolescents aged 11 to 15 with ASD were interviewed. Starting from three general parenting dimensions (warmth, parental control and autonomy support) and two parenting dimensions of particular relevance in ASD (stimulating the development and adapting the environment), our analyses produced an integrated framework with three core dimensions: warmth, behavioral control and stimulation. Our findings suggest that parents make strategic decisions in parenting their children with ASD: they report adapting their behaviors at many levels, although these behaviors per se are not ASD specific.
\end{abstract}

Keywords: Autism spectrum disorder, Parenting behavior, Parenting stress, Early adolescence, Qualitative research 


\section{Introduction}

When children move into adolescence, they are confronted with various challenges due to the many physical, cognitive, social and emotional changes associated with this period (Negriff \& Susman, 2011; Picci \& Scherf, 2014). During early adolescence, peer relationships gain importance, and children are physically and psychologically distancing themselves from their parents (Collins \& Laursen, 2004). The process of becoming more autonomous is often associated with conflicts with parents, which peak in early adolescence in contrast to mid or late adolescence (Laursen, Coy, \& Collins, 1998).

Compared to their typically developing peers, children and adolescents with autism spectrum disorder (ASD) have fewer friends and tend to spend more time with their parents (Solish, Perry, \& Minnes, 2010). A further challenge during early adolescence that may present particular difficulties for children with ASD is the transition from primary to secondary school (Carter et al., 2013; Makin, Hill, \& Pellicano, 2017). Given these age-related changes and ASDrelated vulnerabilities, challenges in parenting children with ASD during this period are to be expected. To date, most studies have focused on parenting stress in the context of raising a child with ASD.

Parenting behaviors have been conceptualized in a number of ways (Lytton \& Romney, 1991). The most commonly identified dimensions in the context of typical development are those proposed by Steinberg, Elmen and Mounts (1989): parental warmth, parental control and autonomy support. Parental warmth refers to parenting behaviors that parents express to show warmth, acceptance and support. Barber (1996) further distinguished two subdimensions within parental control: psychological control and behavioral control. Psychological control is defined as attempts that intrude into the psychological and emotional development of the child, e.g. by 
influencing the child's behavior by making the child feel guilty. Behavioral control refers to parenting behaviors that attempt to control or manage behavior, e.g. rule setting and supervision. Within behavioral control, distinctions have also been made between proactive and reactive control. Parenting behavior that encourages good behavior is called proactive control, whereas reactive control describes responses to the child's behavior (Socolar, 1997). Lastly, autonomy support includes parenting behaviors that encourage the child's volitional functioning, e.g. by allowing choices (Joussemet, Landry, \& Koestner, 2008). In the literature on parenting children with ASD, two further dimensions particularly apparent in ASD have been identified. These have been termed stimulating the development and adapting the environment (Lambrechts, Van Leeuwen, Boonen, Maes, \& Noens, 2011). Stimulating the development refers to behaviors that help a child to acquire specific skills or insights, for example explaining emotions to the child. Adapting the environment, on the other hand, includes parenting behaviors that parents adopt to make things easier for their child, for example keeping distraction to a minimum when the child is doing homework. However, to date, the general and the ASD adapted parenting dimensions have always been discussed separately from each other. Therefore, it is not clear how ASD specific these adapted dimensions are, and how they relate to more general parenting dimensions.

Few studies have addressed parenting teenagers with ASD. Maljaars et al. (2014) assessed parenting behaviors among mothers with a child with and without ASD crosssectionally. In addition to reporting more ASD adapted and positive parenting, they reported lower levels of rules and discipline. Furthermore, specific age effects were found within the ASD group. Parents of older children with ASD reported less adapting the environment and material rewarding, and more stimulating the development compared to the younger age group. A 
longitudinal questionnaire study by Osborne and Reed (2010) with families of children with ASD aged between 2.5 and 16 years old reported lower scores on parental involvement, communication and limit setting compared to general population means, but similar levels of autonomy support. Although most parenting behaviors appeared to be stable over time, communication increased, whereas the lowest scores on limit setting were reported in the older age groups. As such, it appears that the behaviors and strategies of parents of children with ASD differ in certain respects compared to parents of typically developing children, and shift in specific ways across development.

An observational study of maternal parenting behaviors concluded that mothers of school aged children with ASD were rated as lower for provision of structure and sensitivity, compared to mothers of typically developing children (Boonen et al., 2015). Similarly, in the observational study of Beurkens et al. (2013), the overall quality of interaction was rated lower in parents of children with ASD aged 4 to 14 years in comparison with typically developing children.

At present, most studies of parenting behaviors in ASD have taken a top-down approach: using existing questionnaires or observational measures to quantify specific behaviors. Whilst these findings give us a broad insight, it would be useful to find out more about specific behaviors of parents of children with ASD, and how they adapt their behavior to respond to the various challenges of early adolescence.

Studies consistently report that parents of children with ASD experience higher levels of stress compared to parents of children with a typical development (Duarte, Bordin, Yazigi, \& Mooney, 2005; Montes \& Halterman, 2007), those with a child with Down syndrome (Dąbrowska \& Pisula, 2010; Estes et al., 2009) or other developmental disorders (Griffith, Hastings, Nash, \& Hill, 2010; Schieve, Blumberg, Rice, Visser, \& Boyle, 2007). Furthermore, 
parents are at greater risk of developing depression (Benson, 2006; A. S. Carter, MartínezPedraza, \& Gray, 2009), findings supported by a meta-analysis by Hayes and Watson (Hayes \& Watson, 2013). However, little is known about the actual challenges that parents experience when raising their children with ASD, and more generally, their feelings and cognitions in relation to their parenting behavior.

To conclude, young adolescence is a turbulent period which is associated with many changes and challenges for all parents, but it can be even more challenging for parents of adolescents with ASD. However, few studies provide in-depth information regarding the concrete parenting behaviors of these parents. The first aim of this study is to explore which behaviors parents adopt and how these behaviors fit with predefined general parenting dimensions (i.e. parental warmth, parental control, and autonomy support) and ASD adapted parenting dimensions (i.e. stimulating the development and adapting the environment) using a thematic analysis. Next, we explore how these ASD adapted dimensions are related to the general parenting dimensions. The second aim is to compare parenting before and after the transition from primary to secondary school using a cross-sectional design. Our last aim is to explore the cognitions and feelings, both positive and negative, related to parenting behavior.

\section{Method}

\section{Participants}

Parents of seventeen early adolescents (29.4\% girls) took part in this study. The parents chose whether they wanted to both take part, or whether only one parent would be interviewed. In total, eleven mothers, three fathers and three parent couples took part. The families were recruited through a project in which children with ASD receive help with the transition from 
primary to secondary education, through previous studies within our research group, or through an information session for parents of children with ASD. All children had been diagnosed with ASD by a multidisciplinary team including a child psychiatrist. The children were within one year before $(n=9)$ or after $(n=8)$ the transition from primary to secondary school, aged between 11.4 - 14.6 years old. Secondary school is comparable to middle school in the US, and the transition usually occurs around the age of 12 . The number of children within the participating families ranged from one to four, and five participants had a sibling with ASD as well.. Table 1 shows the demographic characteristics of the children, participating parents and family. The group is quite heterogeneous regarding their demographic characteristics, so we assume this does not impact the results.

Table 1. Sample characteristics.

$\begin{array}{lll}\text { Child characteristics }(\boldsymbol{N}=\mathbf{1 7}) & & \\ \text { Age } & \text { Range (months) } & 138-175 \\ & M(S D) & 152(9.7) \\ \text { Gender }(\%) & \text { Boys } & 12(70) \\ & \text { Girls } & 5(30) \\ \text { School }(\%) & \text { Primary school } & 9(52.9) \\ & \text { Regular } & 5(29.4) \\ & \text { Special } & 4(23.5) \\ & \text { Secondary school } & 8(47.1) \\ & \text { General } & 5(29.4) \\ & \text { Technical } & 1(5.9) \\ \text { Vocational } & 2(11.8) \\ \text { Years since diagnosis } & \text { Range (years) } & 1-10 \\ M(S D) & 5.8(2.3)\end{array}$


Parent characteristics $(N=19)$

Informant $(\%)$

Father

$3(18)$

Mother

$11(65)$

Both parents

Age

Range

$38-54$

$M(S D)$

$45(4)$

Education level (\%)

No college

Bachelor degree

$11(58)$

Master degree

$6(32)$

Family characteristics $(N=17)$

$\mathrm{N}$ of children

Range

$1-4$

$M(S D)$

$2.4(.9)$

Marital status (\%)

Single-parent

Cohabitation

Married

$13(76)$

\section{Procedure}

The in-depth interviews were conducted at the parent's home or at the university in a quiet room. No children were present in the room during the interview. After parents provided informed consent, a semi-structured interview was administered. First, the interviewer gave a general introduction in which the purpose of the research was explained. Parents were then asked to introduce themselves and their child with ASD. Subsequently, the corpus of the interview focused on the behaviors, feelings and cognitions associated with parenting the adolescent with ASD. Some examples of the lead questions are: "How do you show your child that you love him/her?", "How do you try to encourage your child to learn certain skills or become more independent?" and "Which situations or aspects of parenting bring a certain amount of stress?". 
Finally, we asked the parents how (the start of) puberty affected their behaviors, feelings and cognitions. The interview durations ranged from 65 to 132 minutes. The interviews were conducted by a research team of five persons, trained by the main interviewee (first author) to ensure consistency. After the interview, parents provided demographic/background information via a questionnaire.

\section{Data analyses}

All interviews were recorded and transcribed verbatim. Nvivo-10 software was used to assist with the analysis. In order to gain insight into the thoughts and behaviors of parents, a case study design using thematic analysis was conducted. The codebook was both inductively and deductively generated. The parenting dimensions, based on relevant literature, were defined as main concepts for further analyses: (1) Parental Control (proactive and reactive behavioral control, psychological control), (2) Warmth, (3) Autonomy Support (4) Stimulating the Development and (5) Adapting the Environment. The first three concepts were based on the framework of parenting in the general population, whereas the latter two were based on the literature on parenting in families with ASD. In the process of coding the interviews, codes for the different parenting behaviors were inductively generated within these over-arching concepts. With regards to the coding of cognitions and feelings about parenting behaviors, no concepts were pre-defined.

As a first step, four interviews were double-coded and subsequently discussed by all five coders together to develop the initial codebook and to familiarize coders with the themes. Next, the remaining interviews were independently coded both by the first coder and one of the other four coders to increase the confirmability of the findings. Codes were subsequently compared 
and differences discussed between the coders until agreement was reached. Then, the behaviors were clustered together and organized into subthemes.

Because we were interested in how general dimensions of parenting behaviors relate to the ASD adapted parenting behaviors, in the next step, we evaluated if and how the subthemes and (general and ASD adapted) dimensions could be reorganized in order to compose an integrated framework. To evaluate the influence of age on parenting behavior, a case-ordered descriptive matrix was built in which the interviews were ordered by the age of the child. Descriptive conclusions were drawn by contrasting behaviors of parents of children in primary with those of secondary school.

\section{Results}

Figure 1 (left) shows the structure of the codebook after coding the interviews. Next, we integrated the general and ASD adapted dimensions. Three adaptations were made (see Fig. 1). Firstly, psychological control, which was initially a subtheme of parental control, was placed within the category reaction to negative behavior within the behavioral control subtheme, since this was only reported as a reaction to undesirable behavior. Secondly, parents reported that behaviors within the adapting the environment theme were used in anticipation of difficult situations. Therefore, adapting the environment was made a subtheme of proactive behaviors, itself a subtheme of behavioral control. One exception was the code for alternative ways to show affection, which was merged with affection within the main theme warmth. Lastly, we integrated the main dimensions, stimulating the development and autonomy support into the new dimension stimulation, because these dimensions were closely connected. The following section presents subthemes and exemplars for the final set of codes described in Fig. 1 (right). In addition, feelings and cognitions regarding these behaviors and age effects are considered. 

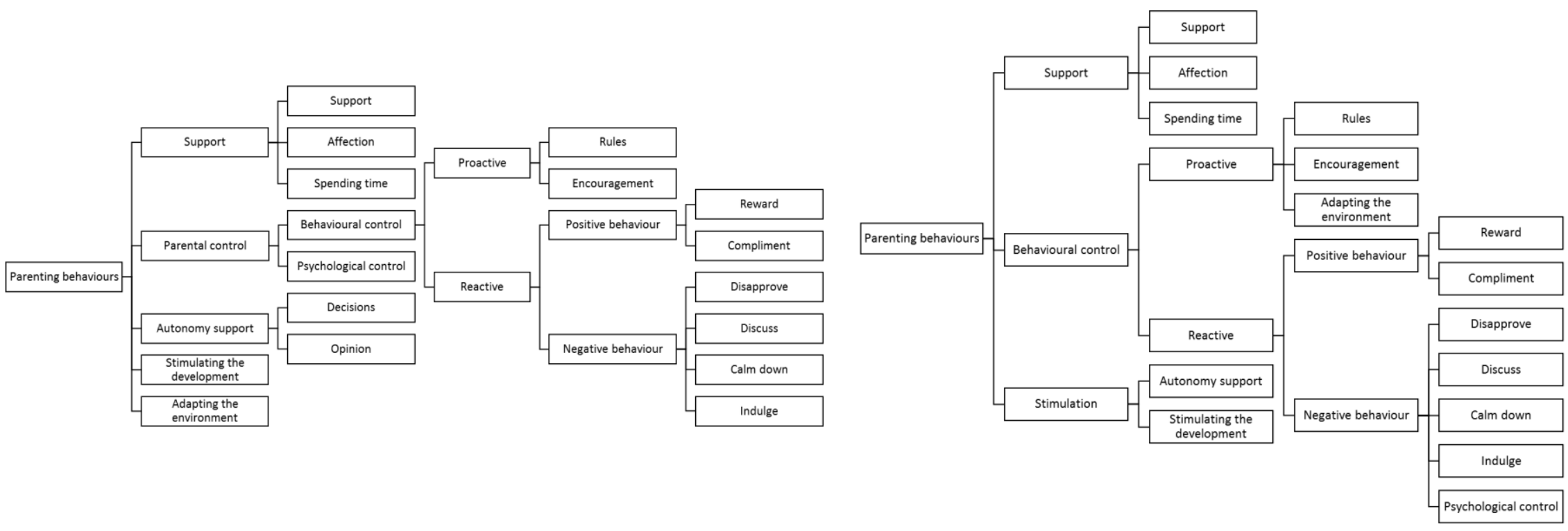

Figure 1. Temporary (left) and final (right) structure of integrative framework of parenting behaviours. The figure should be read from left to right, starting from the overall concept 'Parenting behaviours'. From left to right, subcategories get more specific. 


\section{Warmth}

Parents reported expressing warmth towards their child by showing interest, encouragement and trust, and displaying affection both verbally ${ }^{(1)}$ and non-verbally ${ }^{(2)}$. Additionally, all interviewed parents reported spending free time with their child, and also spending quality time together during daily activities ${ }^{(3)}$, during school related activities, or while doing tasks ${ }^{(4)}$. Some parents indicated that they show affection towards their child in a different way compared to what they might do spontaneously ${ }^{(5)}$.

${ }^{(1)}$ I tell him [that I love him] because I think he understands that better than... than if I hug him or something. He doesn't always like that, like "hmm" he'd say and then he pulls away a little so yeah. So, I mostly tell him "you know mommy loves you." - participant 4

${ }^{(2)} \mathrm{He}$ is quite tactile, so he often loves a good hug and he appreciates it if you hold him close and ... he'll ask for that very often. - participant 12

${ }^{(3)}$ We have a moment every day in the evening when he goes to sleep, he likes me to read a book with him. - participant 2

(4)If you asked our children "tell me about the time you spend together", the first thing they'd always say is “we always clean up together.”. - participant 17

${ }^{(5)}$ And that it looks like it is distant, or otherwise, for outsiders [...] but I cannot say that therefore it has a different effect [...] So it's not because it's different that it is therefore less intense. - participant 14

Regarding the age of the child, parents of children at secondary school tended to report using more verbal strategies to show warmth and spending less time together during daily activities, chores or school related activities compared to parents of children in primary school. 
Several parents reported experiencing difficulties showing affection ${ }^{(1)}$, mostly because their child appeared to have no need for affection. Nevertheless, most parents also indicated that showing warmth and spending time together gives them satisfaction ${ }^{(2)}$.

${ }^{(1)}$...you can hug my youngest daughter much more spontaneously but with $[\mathrm{X}] \ldots$ physical contact is ... I'll say, three-quarters of the time she is not open to it and at other times she is just unbelievably clingy. participant 11

${ }^{(2)}$ And there are moments when we're watching movies together and he'll crawl completely against you in the seat and then he'll say some things about the movie ... it's always very nice. - participant 16

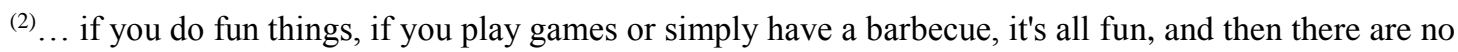
problems. - participant 9

\section{Behavioral Control}

Proactive control. Within proactive control, three clusters were distinguished. Starting with the first cluster, all parents reported setting rules at home. Most parents reported having rules about hygiene and tidiness, screen time, tasks and about social rules such as politeness. Several parents also set rules about homework and time children have to go to bed or get up. Other rules mentioned focused on financial issues, hobbies, food and medication. More than half of the participants indicated that they make rules very explicitly and explain the use of a rule $e^{(1)}$. Most parents indicated they have to repeat the rules frequently and enforce them very closely. More generally, parents tended to monitor their child's daily behavior closely. ${ }^{(2)}$

${ }^{(1)}$ Like [I will say to him] "if you keep on using your phone, you'll have trouble falling asleep and I don't want that, tomorrow you have to be properly rested for school, tests, you name it." More referring as to why I am doing something. - participant 15

${ }^{(2)}$ So there are rules that I really need to monitor closely, because he'll slip away and he'll sit at his computer and then, I can't get him off anymore, and that's difficult. [...] but yeah those are also rules that I have to uphold very strictly and closely. - participant 1 
${ }^{(2)}$ Then for example you'd search her mobile phone for the messages she has sent. I think with my other 13 year-old daughter I would never do that and it would never be accepted. And then [with my ASD daughter] I'd look at her Facebook, I'd look, I would sometimes go nosing around, that doesn't sound polite, but that's really... And she knows that as well, we've talked about it that I monitor a little. Not to control her but to help her, with those situations. - participant 3

The second cluster involved proactive parenting behaviors to encourage the child's positive behavior. Some parents reported that they try to encourage positive behavior by promising a reward ${ }^{(1)}$. Some parents who indicated that it is difficult to encourage their child because he/she lacks confidence reported trying to instill confidence in their child ${ }^{(2)}$, e.g. repeatedly telling the child that they believe in him/her. Some parents reported explaining the positive effects of desirable behavior or negative effects of undesirable behavior ${ }^{(3)}$. Other parents motivate their child to behave well by setting a good example for them to follow.

${ }^{(1)} \mathrm{He}$ very much likes bavarois [type of desert]. And so we'd say, "if you brush your teeth properly every day without fail for a week, you will get a bavarois on Saturday." So he is able to do it. So he knows how he should do it, but you always have to challenge him. Always. - participant 6

${ }^{(2)}$ [in response to a question about how they stimulate their child to do his homework] By approaching him positively. So by saying "yes you can" and "I know you can do it" and that $i$ s true, but he lacks selfconfidence. - participant 9

${ }^{(3)}$ And some things, let me think, like for example the carnival, which is something very difficult for her, to dress up, she thinks, there is no point in doing that. So ... it is sometimes difficult to say to her "yes, for me you don't have to dress up, but tomorrow you are going to be the only, the only girl in class that is not dressed up. Will you be able to handle it if everyone asks you 'why are not you dressed up?' " - participant 17

Regarding the third cluster, most parents reported adapting their behavior, or attempting to make some situations easier for their teenager in order to make unwanted behavior less likely 
to occur. Parents reported adapting their behaviors in several ways. First, parents indicated they adapt their communication ${ }^{(1)}$, both as a strategy to overcome difficulties in receptive communication, e.g. by using very concrete language or working with pictograms; and to encourage expressive communication, e.g. by carefully selecting the time and place when they start a conversation (in the car or when the child is relaxed), by asking open questions, or by using a nonverbal medium, such as drawing. Secondly, most parents reported creating structure, routine and predictability into their daily activities ${ }^{(2)}$. When there is a change of plans, parents reported trying to inform their child about the change as soon as possible, and thoroughly explaining why something would not be happening as planned. Furthermore, parents indicated avoiding certain situations in which they anticipated problems ${ }^{(3)}$. Several parents reported adapting the environment by avoiding certain places, e.g. crowded areas, and choosing a school environment conducive to the child's needs ${ }^{(4)}$. Lastly, several parents reported being very patient and allowing their teenager to take the time they need ${ }^{(5)}$.

${ }^{(1)} \mathrm{He}$ also has said: “a lot of things are bothering me and it's getting all mixed up and it won't stop in my head and..." "Ok, X., tomorrow we'll draw it." [I take a] sheet of paper the next day ... and so I've really been able to draw the things that have been on his mind. - participant 10

${ }^{(2)}$ I'll never say "we're going to drive to grandma's" and then stop at the bakery. - participant 16

${ }^{(2)}$ What we have always done from the beginning is to create predictability, so really saying like "look, what will be the purpose [of this], what will we be doing there?" We show him some pictures, make a plan, show him the plan. And we still notice now, that it's important to him. - participant 7

${ }^{(3)} \mathrm{He}$ doesn't care about presents, because then he has to choose something and then it becomes hard, so we don't really do that anymore. - participant 16

${ }^{(4)}$ We have found a very good school nearby in the neighborhood, so at noon he can still come home to eat so he doesn't have ... a lunch break any more where things can go wrong and ... that's very important participant 4 
${ }^{(5)}$ So I would rather wait 10 more minutes and then he will go along, and he will have a great bike ride, then he's in a good mood. [...] But we would be standing there waiting for 40 minutes until our mister finally wants to come along. - participant 2

In general, the highest levels of proactive parenting behavior were reported by parents of children in primary school, in particular the provision of structure and predictability. There was less evidence for an effect of age on the amount of rules and degree of supervision. However, a shift in the kind of rules set was evident. Parents of older children reported having more rules about hygiene and tidiness at home and fewer rules about bedtimes.

Reactive control. Most parents reported reacting to both desirable and undesirable behavior. Reactions to positive behavior mostly involved praise ${ }^{(1)}$ or a reward. Rewards included both presents of desired objects or access to preferred activities ${ }^{(3)}$.

${ }^{(1)}$ We'd also say "those are really brilliant marks, you have worked so hard." - participant 5

${ }^{(2)}$ For them [the treat is] ... eating something on the couch. Perhaps that's a bit silly but I think that such things, they see them as a reward. - participant 17

When their child does not follow rules or misbehaves, parents most commonly reported reacting by disapproving of the behavior and repeating the rule. Disapproval could be verbal criticism of the behavior or could involve giving the child a punishment ${ }^{(1)}$. Most parents reported discussing the situation with their child rationally, explaining why they thought their child had misbehaved, but also trying to understand why they had behaved that way from the child's perspective. Many parents indicated that emotions could run high in such situations, so they initially attempt to calm their child by giving him or her a time-out ${ }^{(2)}$, e.g. asking the child to go to his/her room, or giving him/her the opportunity to vent their anger in a safe space. Some parents indicated that they don't always discipline their child and instead just accept problem behavior $^{(3)}$. The most common reasons for this were being tired of putting energy into enforcing 
particular behaviors and avoiding discussions or escalation of problem behavior. Similarly, some parents reported reducing requests when the child opposed them ${ }^{(4)}$. Only one parent reported using psychological control, namely guilt induction, as a reaction to undesirable behavior ${ }^{(5)}$.

${ }^{(1)}$ Cleaning up is now linked to pocket money. If her room is not tidy on Sunday, she will not get her pocket money. - participant 5

${ }^{(2)}$ Or if he's really ... acting out, we need to... soothe him .. yes, by placing him out of the room, so still ... putting him in the corner is difficult, but err, still taking him somewhere where he is on his own and saying “you'll stay here and you will calm down or you will go to your room and you'll wait until you are calm." participant 12

${ }^{(2)}$ I let him blow off steam outside or he must go upstairs and then he can throw his teddies. I'll only try to engage in some kind of communication once he has let it all out. That's not possible at that moment. participant 14

${ }^{(3)}$ And yes, I refuse to check [how well he brushed] his teeth every day, I'm like "well, by now he should..." and he's got an electric toothbrush. How he does it, I don't know, but his teeth are not properly cleaned. Even with an electric toothbrush. - participant 6 ${ }^{(4)}$ I'll give in, but basically what I'm trying to do is not push her further on this, this inflexibility where she'll get completely stuck, by possibly allowing something - that again is educationally incorrect - to allow something small in order to avoid something larger, in order to avoid a larger problem. - participant 13 ${ }^{(5)}$ We'll usually say something along the lines of "I think it's bad that $d a d$ has to go check on the list who has to dry the dishes," because I think they can do this as well [...] when I've cooked and I've put food on the table, then $I$ still have to go and see who should clear the table? - participant 8

Parents of younger children reported rewarding their child more often in response to good behavior. Although parents of all children reported using similar strategies (e.g. punishment, explaining the consequences...) in response to undesirable behavior, permissive strategies (e.g. reducing the request to avoid disagreements with their child) were more apparent in parents of children in primary school. 
Almost all parents reported experiencing difficulties in managing their child's behavior. A first cluster of difficulties related to characteristics and/or behavior of the child. Most parents reported experiencing difficulties because their child does not follow instructions or challenges them ${ }^{(1)}$. Other difficulties highlighted in the interviews related to problems with daily activities ${ }^{(2)}$, managing the child's behavior when the parent is not present, or regarding social issues or issues considered private ${ }^{(3)}$. Additionally, some parents consider their child difficult to punish ${ }^{(4)}$. Furthermore, some problems seemed to stem from a discrepancy between parents' expectations of being able to reduce their guidance at this age and the actual reality that they are confronted with $^{(5)}$.

${ }^{(1)}$ You constantly have to supervise this. You need to actually constantly remain with him, you can't say 'do this now' and then go away. You have to stay there almost always. - participant 2

${ }^{(2)} \mathrm{He}$ has his own cell phone where he enters when he needs to shower, when he should brush his teeth ... but then, he'd leave it downstairs, he wouldn't hear it, and then I'd have to go call him every time "Now you have to go wash," well, that's ... difficult, and it is also difficult to make him learn, to encourage him to get into the habit. That's not very, not very pleasant. - participant 4

${ }^{(3)}$ At times I have to search how far I can go in controlling. [...] I still have to figure it out how to do things, like discussing your daughter's bikini line with her. - participant 3

${ }^{(4)} \mathrm{He}$ is not very susceptible to punishment. He was like “yes, you do, but if I cannot watch TV today, I won't watch TV, I'll do something else.” And that's, that's very difficult with him. - participant 7

${ }^{(5)}$ You still have to tell him, well, the basic things that he actually is supposed to do like "put on your clothes" and then "no, not those clothes, fresh clothes." It [parenting] is sometimes really still at kindergarten level. participant 12

${ }^{(5)}$ The amount of behavioral control is still the same, and I think that's a pity. I had hoped that I would have to control less, that he would be more independent, and err..., that it would go well. Also [I'd hoped he would gain independence] by going to secondary school. - participant 2 
Worries about private and social issues and unmet expectations became more prominent in parents of older children, as illustrated above. However, several parents also indicated that their child behaves very well and follows the rules strictly.

Once you have made an agreement, then it'll be like that. As a result, she also has a great sense of responsibility. - participant 11

He will also be honest and set his alarm at the right time, he won't cheat or ... he won't favor himself like a little bit. He is very honest in these things. participant 12

\section{Stimulation}

Two subthemes were generated within this theme: autonomy support and stimulating the development of certain skills. Within autonomy support, most parents reported encouraging their child to form opinions and take decisions. Instances where parents delegate decision making to their children were identified. First, most parents indicated that their child participates in personal decisions ${ }^{(1)}$ such as what to do during their free time, what clothes to wear, but also more important personal decisions, such as picking a school. Next, children were granted some autonomy regarding house rules, for example sleeping hours, pocket money or time spent using multimedia. Finally, children were reportedly given a say in family decisions ${ }^{(2)}$, like holidays or the choice of a new car.

${ }^{(1)}$ When she went to secondary school, we also re-decorated her room at the same time, she also had a say in that, yes ... the colors in her room and the closets and you know. - participant 11

${ }^{(2)}$ You can involve him actually with a lot of things, even when choosing a new car and when... some financial considerations of "yes we could buy that, but it costs that amount, this is also nice but it costs less" without letting him decide. But you can involve him in things and let him have a say in it. participant 7

However, in contrast, some parents also reported avoiding asking their child to make decisions $^{(1)}$ or form an opinion ${ }^{(2)}$. 
${ }^{(1)} \mathrm{He}$ is not good at making decisions. [...] So we avoid that very often, offering choices, because that ... for him ... yes, that makes the situation quite uncomfortable. - participant 12

${ }^{(2)}$ I listen to [his opinion] but... usually it is actually unrealistic, about certain things... well yes, it is mainly about things, material things actually. - participant 1

Furthermore, parents reported encouraging their child to develop certain skills. They also instigate social interactions and activities. Parents also reported teaching their child to improve their organizational skills, time management, and academic skills.

Parents of children in secondary school reported supporting their child to form opinions and experience social contacts more frequently than did parents of children in primary school. Similarly, these parents more often allowed their child to have a say in bedtimes, pocket money and personal decisions. On the other hand, parents of children in primary school reported stimulating the development of social skills more often.

Parents often reported concerns in relation to this dimension ${ }^{(1)}$. Most commonly, parents addressed the amount of effort required to teach their child something. Some parents reported having difficulty allowing the child more freedom. Parents of younger children tended to express more worries about how to increase their child's independence and encourage them to develop skills. However, most parents also reported feeling satisfied when their adolescent gained skills and became more independent ${ }^{(2)}$.

${ }^{(1)}$ Letting her go is just like biting on your lip, but to give an example ... I always remember, I have taught four children to ride a bicycle. And the youngest said, "Hey mom, can you teach me to ride a bike?" [...] she pedals and she is gone. With X, you needed to run behind her for hours [...]. At some point you have to let go, and you'd actually be like "just do it now". And then she falls and it hurts so much on the inside if she falls. [...] because what she is capable of, at the moment you let her go, it is just less and therefore the trial and error much more ... - participant 3 
${ }^{(2)}$ The positive feeling you get when you think back to how it was in the first year of primary school and how she behaves now as a person, of course you get a lot of satisfaction. - participant 11

\section{Discussion}

This study attempted to capture how parents raise their child with ASD in early adolescence and how their parenting behaviors fit within an integrated conceptual framework of parenting. The results revealed that the ASD adapted parenting dimensions (stimulating the development and adapting the environment) could not be considered completely independent from the general parenting dimensions (warmth, parental control and autonomy support). Parents indicated that they often adapt their behavior to meet the needs of their child with ASD, although these behaviors in themselves are not ASD specific. Therefore, these dimensions were integrated, resulting in a structure with three dimensions (warmth, behavioral control and stimulation), each including accommodations to adapt to the specific characteristics and vulnerabilities of the child with ASD.

The first dimension, parental warmth, encompasses support, affection and time spent together. However, some children seem to have a lower need for affection, aversion for hugs, or display socially inadequate behaviors. Therefore, many parents of early adolescents with ASD consciously think about the proper manner and timing to show their love and support. Furthermore, it can be difficult to find common interests to spend time together, while taking into account the specific vulnerabilities of the children, such as restricted interests, adherence to routine and overstimulation in crowded placed. Parents overcame these difficulties by planning trips ahead, showing pictures in advance, working with a visual week planning, relegating theme park visits to rainy, quiet days etc. 
The second dimension, behavioral control includes all proactive and reactive behaviors that intend to control the behavior of the child. Most parents indicated that this can be challenging, for example because their child does not follow instructions, has difficulties internalizing daily routines, or does not stay focused on a chore. Parents adopt specific parenting behaviors to overcome these difficulties, such as giving one task at a time, making rules very explicit, visualizing chores, explaining behind rules, explaining the possible result of unwanted behaviors, or making unwanted behavior impossible for example by throwing away old clothes that the early adolescent is not supposed to wear anymore. In addition, many adaptations that were first seen as ASD adapted parenting behaviors, appeared to function as proactive parenting behaviors to avoid difficult situations or prevent undesirable behaviors, for example by creating structure, routine and predictability into their daily activities.

The last dimension is stimulation which is a combination of the general parenting dimension Autonomy support and the ASD adapted parenting dimension Stimulating the development. Most parents reported encouraging their child to form opinions and take decisions. However, some children have difficulties to take decisions and to gain independence. Therefore, some parents take decisions in their place, or offer choices instead of posing open questions. In addition, parents try to stimulate the development of their children in order to overcome vulnerabilities, for example encouraging independence, social contacts, activities and social skills. However, we noticed that parents tend to be restrained in offering opportunities in which their early adolescent can develop skills him/herself. In contrast, parents seem to adopt a more controlling approach in which they teach their child step-by-step how to master a specific skill.

Although we only focused on one year before and after the school transition, some patterns in parenting behaviors were apparent. Within the dimension warmth, parents of children 
in secondary school reported using more verbal strategies to support their child and also reported spending less time with their child. Regarding behavioral control, most parenting behaviors within proactive control and reaction to good behavior seemed to decrease with the transition to secondary school. These results are in line with previous findings (Maljaars et al., 2014), which also reported a decrease in material rewarding and adapting the environment by parents of adolescents with ASD compared to those with primary school aged children. Although behaviors that can be considered permissive, such as allowing undesirable behavior to happen or reducing requests were reported by parents of children in primary school, these behaviors were rare among parents of children in secondary school.

Several parents expressed that they still have to manage their child's behavior more than they would like and more than they would have expected to do by this age. There appeared to be a shift in the skills that parents attempted to stimulate as their child got older. Parents of children in primary school focused more on the development of prosocial skills. These parents also appeared to worry more about how to increase their child's independence. Parents of children in secondary school reported attempting to encourage their child to develop more autonomy, whereas behaviors that involved preventing their child from having to make decisions or form an opinion were rare.

\section{Limitations and Future Research Directions}

Several limitations should be noted. A first limitation is that only parents were interviewed, so there was no information regarding the perspectives of teenagers themselves. Conversely, a strength of this study was the inclusion of mothers, fathers, or both parents, and the broad range in terms of parental education levels and family characteristics. Similarly, a variety of children with ASD are represented, regarding sex, education level and the age at which 
they received the diagnosis. Secondly, the results provide very rich information regarding parenting behaviors. However, the answers might be biased by social desirability, given that none of these parents reported physical punishments, and only one parent described behaviors that could be interpreted as psychological control. A further limitation is the cross-sectional design of this study, which makes it difficult to interpret the age effects found.

We think this study can provide a basis for future research. To bridge limitations related to our cross-sectional design, a longitudinal design would provide more insight into how parenting behavior evolves over time in the context of ASD. Another suggestion for further research is to conduct a similar interview with parents of typically developing children. It would be interesting to know whether parents of children without ASD employ qualitatively similar behaviors and whether the same relationships with age are evident. Furthermore, this study offers specific suggestions about how parents deal with the challenges of parenting an early adolescent with ASD at the behavioral level, e.g. how parents provide proactive control to an adolescent with ASD. It would be useful to investigate how effective these suggestions are, and whether they are associated with for example a decrease in parenting stress or behavior problems of the child. Next, this study concluded that ASD adapted parenting dimensions cannot be differentiated from the general parenting dimensions. Further research could empirically investigate the association between ASD adapted and general parenting dimensions. Furthermore parents reported a variety of feelings and cognitions about their parenting behaviors. Behaviors that were experienced as positive by some parents (e.g. showing affection or doing activities together) were stressful for other parents, whereas behaviors that were challenging for some parents (e.g. applying rules) seemed to be very natural for other parents. It appears useful to 
study the association between stressful and satisfying factors in parenting, and the quantity and quality of their parenting behaviors. Based on this study, we could on the one hand hypothesize a negative association between the quantity of parenting behaviors and negative feelings associated with this behavior, because it is possible that parents avoid stressful parenting behaviors. On the other hand, a positive association could be hypothesized as well, as parents in this study reported that some parenting behaviors were stressful for them because they have to implement them so often, implying a higher quantity of these stressful behaviors. In addition, we assume that the manner in which they do something, e.g. the quality of homework supervision, is also dependent on how relaxed or stressed the parent is when doing so.

\section{Acknowledgments}

This research was funded by the Research Fund KU Leuven, University of Leuven (OT/13/051). Furthermore, we thank all the participating families. 


\section{References}

Barber, B. K. (1996). Parental psychological control: revisiting a neglected construct. Child Development, 67(6), 3296-3319. https://doi.org/10.2307/1131780

Benson, P. R. (2006). The impact of child symptom severity on depressed mood among parents of children with ASD: the mediating role of stress proliferation. Journal of Autism and Developmental Disorders, 36(5), 685-695. https://doi.org/10.1007/s10803-006-0112-3

Beurkens, N. M., Hobson, J. A., \& Hobson, R. P. (2013). Autism severity and qualities of parent-child relations. Journal of Autism and Developmental Disorders, 43(1), 168-178. https://doi.org/10.1007/s10803-012-1562-4

Boonen, H., van Esch, L., Lambrechts, G., Maljaars, J., Zink, I., Van Leeuwen, K., \& Noens, I. (2015). Mothers' parenting behaviors in families of school-aged children with autism spectrum disorder: an observational and questionnaire study. Journal of Autism and Developmental Disorders, 45(11), 3580-3593. https://doi.org/10.1007/s10803-015-25066

Carter, A. S., Martínez-Pedraza, F. de L., \& Gray, S. A. O. (2009). Stability and individual change in depressive symptoms among mothers raising young children with ASD: maternal and child correlates. Journal of Clinical Psychology, 65(12), 1270-1280. https://doi.org/10.1002/jclp.20634

Carter, E. W., Common, E. A., Sreckovic, M. A., Huber, H. B., Bottema-Beutel, K., Gustafson, J. R., ... Hume, K. (2013). Promoting social competence and peer relationships for adolescents with autism spectrum disorders. Remedial and Special Education, 35(2), 91101. https://doi.org/10.1177/0741932513514618 
Collins, W. A., \& Laursen, B. (2004). Changing relationships, changing youth interpersonal contexts of adolescent development. The Journal of Early Adolescence, 24(1), 55-62. https://doi.org/10.1177/0272431603260882

Dąbrowska, A., \& Pisula, E. (2010). Parenting stress and coping styles in mothers and fathers of pre-school children with autism and Down syndrome. Journal of Intellectual Disability Research, 54(3), 266-280. https://doi.org/10.1111/j.1365-2788.2010.01258.x

Duarte, C. S., Bordin, I. A., Yazigi, L., \& Mooney, J. (2005). Factors associated with stress in mothers of children with autism. Autism, 9(4), 416-427. https://doi.org/10.1177/1362361305056081

Estes, A., Munson, J., Dawson, G., Koehler, E., Zhou, X.-H., \& Abbott, R. (2009). Parenting stress and psychological functioning among mothers of preschool children with autism and developmental delay. Autism, 13(4), 375-387. https://doi.org/10.1177/1362361309105658

Griffith, G. M., Hastings, R. P., Nash, S., \& Hill, C. (2010). Using matched groups to explore child behavior problems and maternal well-being in children with Down syndrome and autism. Journal of Autism and Developmental Disorders, 40(5), 610-619. https://doi.org/10.1007/s10803-009-0906-1

Hayes, S. A., \& Watson, S. L. (2013). The impact of parenting stress: A meta-analysis of studies comparing the experience of parenting stress in parents of children with and without autism spectrum disorder. Journal of Autism and Developmental Disorders, 43(3), 629642. https://doi.org/10.1007/s10803-012-1604-y 
Joussemet, M., Landry, R., \& Koestner, R. (2008). A self-determination theory perspective on parenting. Canadian Psychology/Psychologie Canadienne, 49(3), 194-200. https://doi.org/10.1037/a0012754

Lambrechts, G., Van Leeuwen, K., Boonen, H., Maes, B., \& Noens, I. (2011). Parenting behavior among parents of children with autism spectrum disorder. Research in Autism Spectrum Disorders, 5(3), 1143-1152. https://doi.org/10.1016/j.rasd.2010.12.011

Laursen, B., Coy, K. C., \& Collins, W. A. (1998). Reconsidering changes in parent-child conflict across adolescence: a meta-analysis. Child Development, 69(3), 817-832.

Lytton, H., \& Romney, D. M. (1991). Parents' differential socialization of boys and girls: a meta-analysis. Psychological Bulletin, 109(2), 267-296. https://doi.org/10.1037/00332909.109.2.267

Makin, C., Hill, V., \& Pellicano, E. (2017). The primary-to-secondary school transition for children on the autism spectrum: a multi-informant mixed-methods study. Autism and Developmental Language Impairments, 2. https://doi.org/10.1177/2396941516684834

Maljaars, J., Boonen, H., Lambrechts, G., Van Leeuwen, K., \& Noens, I. (2014). Maternal parenting behavior and child behavior problems in families of children and adolescents with autism spectrum disorder. Journal of Autism and Developmental Disorders, 44(3), 501-512. https://doi.org/10.1007/s10803-013-1894-8

Montes, G., \& Halterman, J. S. (2007). Psychological functioning and coping among mothers of children with autism: a population-based study. Pediatrics, 119(5), e1040-e1046. https://doi.org/10.1542/peds.2006-2819 
Negriff, S., \& Susman, E. J. (2011). Pubertal timing, depression, and externalizing problems: a framework, review, and examination of gender differences. Journal of Research on Adolescence, 21(3), 717-746. https://doi.org/10.1111/j.1532-7795.2010.00708.x

Osborne, L. A., \& Reed, P. (2010). Stress and self-perceived parenting behaviors of parents of children with autistic spectrum conditions. Research in Autism Spectrum Disorders, 4(3), 405-414. https://doi.org/10.1016/j.rasd.2009.10.011

Picci, G., \& Scherf, K. S. (2014). A two-hit model of autism adolescence as the second hit. Clinical Psychological Science, 3, 349-371. https://doi.org/10.1177/2167702614540646

Schieve, L. A., Blumberg, S. J., Rice, C., Visser, S. N., \& Boyle, C. (2007). The Relationship between autism and parenting stress. Pediatrics, 119(Supplement), S114-S121. https://doi.org/10.1542/peds.2006-2089Q

Socolar, R. R. S. (1997). A classification scheme for discipline: type, mode of administration, context. Aggression and Violent Behavior, 2(4), 355-364. https://doi.org/10.1016/S13591789(97)00021-9

Solish, A., Perry, A., \& Minnes, P. (2010). Participation of children with and without disabilities in social, recreational and leisure activities. Journal of Applied Research in Intellectual Disabilities, 23(3), 226-236. https://doi.org/10.1111/j.1468-3148.2009.00525.x

Steinberg, L., Elmen, J. D., \& Mounts, N. S. (1989). Authoritative parenting, psychosocial maturity, and academic success among adolescents. Child Development, 60(6), 14241436. https://doi.org/10.2307/1130932 